\title{
Bakımda Yeni Bir Yaklaşım: Travma Bilgisi İçeren Bakım
}

\section{A New Approach to Care: Trauma Informed Care}

\author{
Müjde Çalıkuşu İncekar ${ }^{1}$ (D) Mary Coughlin² ${ }^{2}$ Zerrin Çiğdem ${ }^{3}$ \\ ${ }^{1}$ Yüksek İhtisas Üniversitesi Sağlık Bilimleri Fakültesi Hemşirelik Bölümü Çocuk Sağlığı ve Hastalıkları Hemşireliği Anabilim Dalı, \\ Ankara, TÜRKIYY \\ ${ }^{2}$ President and Founder of Caring Essentials Collaborative, Boston, USA \\ ${ }^{3}$ Hasan Kalyoncu Üniversitesi Sağlı Bilimleri Fakültesi Hemşirelik Bölümü, Gaziantep, TÜRKIYYE
}

Geliş tarihi/ Date of receipt: 04/06/2020 Kabul tarihi/ Date of acceptance: 05/08/2020

(C) Ordu University Faculty of Health Sciences, Department of Nursing, TURKEY, Published online 30/09/2020

\begin{abstract}
ÖZ
Yenidoğan Yoğun Bakım Üniteleri’nde (YYBÜ) travma bilgisini içeren bakım yaklaşımını uygulamak, preterm ve yüksek riskli yenidoğanların kısa ve uzun dönem sonuçlarını iyileştirmede yaşamsal öneme sahiptir. Yaşamın en erken ve en savunmasız evresindeki bu bebeklerin bakım sürecini travma gözüyle değerlendiren sağlık çalışanları, yenidoğanın hastanede yattığı dönemde beyin gelişimini daha iyi destekleyerek erken dönem olumsuz yaşam deneyimini hafifletebilir. YYBÜ’de olumsuz uyaranların varlığ 1 ve olumlu uyaranların eksikliği, bebek için yıkıcı olan önemli stres etmenlerini oluşturur. Riskli yenidoğanlar için olası toksik stres faktörleri; YYBÜ'nin fiziksel çevresinden (parlak aydınlatma, yüksek sesler, zararlı kokular gibi), psikososyal ortamından (el tutma, sarmalama, kanguru bakımı, olumlu duyusal uyaranlardan yoksun bırakılma gibi destekleyici sosyal etkileşimlerin olmaması) ve klinik uygulamalarından (bebeğin sağlı̆̆ı ve güvenliği için gerekli klinik prosedürler) kaynaklanabilir. Travma bilgisi içeren yaşa uygun bakım, hayatın başında travmanın fizyolojik, nörobiyolojik ve duygusal boyutta olumsuz etkilerini tanıyan gelişimsel bir kavramdır ve kanıta dayalı, yaşa uygun bakım stratejileri ile travma deneyimine ilişkin zararlı etkileri hafifletmeyi amaçlar. Bu kavram klinik uygulamada yenidoğanın daha sonraki yaşamında temel fiziksel, bilişsel, sosyal ve duygusal olarak sağlık ve iyiliğini korumak ve güvenliğini sağlamak için uygun bir çevre oluşturur. Travma bilgisi içeren bakım ile yüksek riskli yenidoğanların, ebeveynlerinin ve sağlık çalışanlarının YYBÜ'de travmadan korunması, var olan travma durumunda gerekli tedavi ve bakımların uygulanması ve travma sonrası üçüncül korumanın sağlanmasına yönelik yaklaşımlar ele alınmalıdır.
\end{abstract}

Anahtar kelimeler: Hemşirelik, preterm, travma bilgisi içeren bakım, yenidoğan yoğun bakım

\begin{abstract}
Applying trauma informed care approach in the Neonatal Intensive Care Units (NICU) has a vital importance in improving the short and long term outcomes of preterm and high risk newborns. Clinicians, who evaluate the care process of these newborn in the earliest and most vulnerable stage of life, can support the brain development during the hospitalization period of the newborn and alleviate the early negative life experience. The presence of negative stimuli and lack of positive stimuli in NICU creates important stress factors that are destructive for the infant. Possible toxic stress factors for risky newborns; NICU's physical environment (as bright lighting, loud sounds, harmful odors), psychosocial environment (lack of supportive social interactions such as holding, swaddling, kangaroo care, deprivation of positive sensory stimuli) and clinical practices (clinical procedures required for the health and safety of the infant). Age-appropriate with trauma informed care is a developmental concept that recognizes the physiological, neurobiological, and emotional negative effects of trauma at the beginning of life, and aims to alleviate the harmful effects of evidence-based, age-appropriate care strategies and trauma experience. This concept creates an appropriate environment in clinical practice to protect the basic physical, cognitive, social, emotional health and well-being of the newborn and to ensure its safety. Approaches to protect high-risk neonates, their parents and clinicians from trauma in the NICU, to apply the necessary treatment and care in case of existing trauma, and to provide tertiary protection after trauma.
\end{abstract}

Keywords: Neonatal intensive care, nursing, preterm, trauma informed care

ORCID IDs of the authors: MÇİ: 0000-0002-4472-2406; MC: 0000-0002-2527-5700; ZÇ: 0000-0001-9420-0131

Sorumlu yazar/Corresponding author: Dr. Öğr. Üyesi Müjde ÇALIKUŞU İNCEKAR

Yüksek İhtisas Üniversitesi Sağlık Bilimleri Fakültesi Hemşirelik Bölümü Çocuk Sağlığı ve Hastalıkları Hemşireliği Anabilim Dalı, Ankara, TÜRKIYE

e-posta/e-mail: mujdecalikusu@gmail.com

Atıf/Citation: Çalıkuşu İncekar M, Couglin M, Çiğdem Z. (2020). Bakımda yeni bir yaklaşım: travma bilgisi içeren bakım. Ordu Üniversitesi Hemşirelik Çalışmaları Dergisi, 3(2), 176-184.

DOI: $10.38108 /$ ouhcd.746215 


\section{Giriş}

Dünya'da her yıl yaklaşık 15 milyon preterm bebek dünyaya gelmekte (DSÖ, 2018; Liu ve ark., 2016) ve ülkemizde bu oranın 2018 verilerine göre \% 15,6 olduğu görülmektedir (Sağlık Bakanlığı, 2019). Normal doğum ağırlıklı yenidoğanların yaklaşık \% 4'ü ve düşük doğum ağırlıklı yenidoğanların \% 85'i her yıl yüksek teknoloji ile donatılmış olan YYBÜ'lerindede yatırılmaktadır (Weber ve Harrison, 2019). YYBÜ, bu kırılgan bebekler için doğumdan sonra olağanüstü hayat kurtarıcı önlemler sunabilmesine karşın; anneden ayrılma, ağrı, sosyal izolasyon, uykusuzluk ve hipotalamikhipofiz-adrenal (HPA) eksenini etkinleştiren çevresel özellikler (stresörler) nedeniyle kritik hastalığı olan bu bebeklerde travmatik bir süreçtir (Coughlin, 2017; D'Agata ve ark., 2016; Montirosso ve Provenzi, 2015). YYBÜ'de karmaşık, çok boyutlu (fiziksel, psikososyal, klinik uygulama), ac1 veren olumsuz uyaranların varlığı ve gelişimsel olarak destekleyici uyaranların eksikliği bu kırılgan bebeklerin öncelikle beyin gelişimleri olmak üzere diğer sistemlerinde de önemli ve y1kıcı stres etkenlerini oluşturmaktadır (Weber ve ark., 2012). Yenidoğanlar YYBÜ'de yattıkları süre boyunca günde yaklaşık 70 stresli işlem ile karşılaşmakta ve bu da bebeğin gelişmekte olan beyninde kalıcı ve olumsuz değişimlere neden olmaktadir (Weber ve Harrison, 2019).

Son dönemlerde yapılan çalışmalarda hastaneye yatmanın yüksek riskli yenidoğan için toksik strese neden olduğuna ve sonuçları önemli ölçüde iyileştirmek için hemşireler tarafindan toksik stresin ele alınması gerektiğine vurgu yapılmaktadır (Shonkoff ve ark., 2012; Weber ve Harrison, 2019). Günümüzde YYBÜ'de yatmanın bebek ve ailesi için travma deneyimi olduğunun kavranılması ile birlikte preterm ve yüksek riskli yenidoğanlara zamanında ve yaşa uygun girişimlerin uygulanması/ ele alınması önem kazanmıştır (Coughlin, 2014). YYBÜ'de travma bilgisi içeren bakıma yönelik bakış açısını getirmek; preterm ve yüksek riskli yenidoğanların kısa ve uzun dönem olumsuz sağlık sonuçlarını iyileştirecek (Grasso ve ark., 2013), bakım sürecininin bu yaklaşım ile yönetilmesi, YYBÜ sağlık çalışanlarının aile merkezli bakım anlayışı ile bebeğin hastanede yattığ 1 dönemde beyin gelişimini desteklemelerine ve nöral hücre ölümlerini azaltmalarına (noroprotektif yaklaşım) olanak sağlayacaktır (Coughlin, 2017; Milette ve ark., 2017; Sprenath ve ark., 2011; Taş Arslan ve Akkoyun, 2019).

$\mathrm{Bu}$ derlemenin amac1, preterm ve riskli bebeklerin içinde bulundukları koşullar nedeniyle yaşamlarının başında ve en duyarlı oldukları dönemlerinde travmanın fizyolojik, bilişsel, duygusal ve duyusal sekellerini gözden kaçırmayan, erken dönemde tanıyan ve bu bebekler için bir hak olan travma bilgisi içeren yaşa uygun bakım yaklaşımı hakkında bilgi vermektir.

\section{Yenidoğan Yoğun Bakım Üniteleri'nde Toksik Stress}

Genel olarak stres, olumsuz bir olaya veya zorlu bir duruma karşı nörolojik, endokrin ve bağışıklık sistemlerinde biyokimyasal değişiklikleri içeren fizyolojik bir başa çıkma yanıtı olarak tanımlanmaktadır. Stres yanıtı, Hipotalamik-Hipofiz-Adrenokortikal (HPA) ekseni, sempatik sinir sistemi, nörotransmitter sistemi ve bağışıklık sistemi gibi yapılar ve sistemleri kapsamaktadır (Selye, 1976). "Toksik stres" terimi, bebek/çocuk için stresin en zararlı şekli olup, "yetişkin desteğinin herhangi bir tamponlama koruması olmaksızın" ortaya çıkan şiddetli, sık ve uzun süreli sıkıntılarla tetiklenen stres türüdür (Shonkoff ve ark., 2012). Bu anormal stres yanıt1, uzun süreli kortizol aktivasyonu ve kalıcı bir inflamatuar durum ile sonuçlanan nöro-endokrin-immün yanıtın düzensizliğine neden olur ve organizma stres etkeni giderildikten sonra bile ortaya çıkan değişiklikleri normalleştiremez (Montirosso ve Provenzi, 2015; Weber ve Harrison, 2019). Özellikle araştırmalar, bebek/çocuğun destekleyici, özenli ve koruyucu yetişkin bakımına erişiminin, HPA sisteminin aktivitesini tamponlamada ve gelişmekte olan beyni stres faktörlerinin potansiyel zararlı 
etkilerinden korumada belirgin bir rol oynadığını ortaya koymuştur (D'Agata ve ark., 2016; Montirosso ve Provenzi, 2015).

Toksik stresin temel özelliği; gelişmekte olan ve çevresel stresörlere en duyarlı gelişim döneminde olan beyin yapısında (anatomik ve fonksiyonel), vücut sistemlerinde ve metabolizmada ortaya çıkan bozulmalardır. Bu tür bozulma, öğrenme ve davranıştaki sorunların yanı sıra, yaşam boyu etkili olacak olan stresle ilgili fiziksel ve zihinsel hastalıkların temelini oluşturan anatomik değişikliklere/fizyolojik düzensizliklere neden olmaktadır (Coughlin, 2017; Sanders ve Hall, 2018). Bu bozulmalar Felitti ve arkadaşları (1998) tarafından "Olumsuz Çocukluk Çağı Deneyimleri (Adverse Childhood Experiences-ACEs)" olarak tanımlanmıştır. Toksik stresin neden olduğu yaşamın erken dönemlerinde ortaya çıkan gelişimsel ve biyolojik bozulmalar, ileri dönemde bireyin sağlığını, gelişimini ve konforunu olumsuz şekilde etkilemektedir (Sanders ve Hall, 2018). Yazarlar, fiziksel, duygusal, cinsel istismarı da kapsayan toksik strese neden olan on olay belirlemişler ve bir çocuğun çoklu Olumsuz Çocukluk Çağ deneyiminin hem fiziksel hem de duygusal sağlığının ve yetişkin olarak iyi olmasının önemli bir belirleyicisi olduğu sonucuna varmışlardır. Bununla birlikte, yazarlar bu belirteçlere HPA ekseninin aracılık ettiğini ileri sürmüşlerdir (Ash ve Williams, 2016; Felitti ve ark., 1998; Shonkoff ve ark., 2012). Cohen ve Wills tarafindan 1985 yılında sosyal desteğin stres altındaki bireyleri stresin olumsuz etkilerine karşı tampon görevi görerek koruduğunu ileri süren tamponlama modeli geliştirilmiştir. Bebek/çocuk bir stresörle karşılaştığında anne ya da babasının/bakıcısının gösterdiği tepki ve tamponlama çok önemli olmaktadır (Johnstone ve ark., 2013). Bebek/çocuğun destekleyici, özenli ve koruyucu yetişkin bakımına erişiminin, HPA sisteminin aktivitesini tamponlamada ve gelişmekte olan beyni stres faktörlerinin potansiyel zararlı etkilerinden korumada belirgin bir rol oynamaktadır (Gunnar ve Donzella, 2002). Hastaneye yatırılan riskli yenidoğanlar için potansiyel olarak toksik stres etkenleri; stres yanitlarını tamponlayacak olan ebeveynlerinden uzun süre ayrı kalma (D'Agata ve ark., 2016; Flacking ve ark., 2012), parmak tutma, sabit dokunma, kolaylaştırılmış fleksiyon, besleyici olmayan emme, toplu bakım verme, sarmalama gibi kanıt temelli girişimleri içeren destekleyici bakımın verilmemesi, çevresel destek olmadan tekrarlanan ağrı-acı veren uygulamalar, uykusuzluk (D'Agata ve ark., 2016; Montirosso ve ark., 2016) ve hizla gelişmekte olan beyni olumsuz etkileyen gürültü, parlak 1şık, aşırı dokunma gibi duyusal çevredir (Als ve ark., 2004). Erken doğmuş bebekler başlangiçta akut strese abart1lı tepkiler verebilse de, otonomik ve nöroendokrin tepkileri stres arttıkça körleşebilir ve sonuçta kronik stresle karşılaşıldığında aşırı duyarlılığa yol açabilir (Victoria ve Murphy, 2016).

Yapılan birçok çalışma, YYBÜ'de yatan bebeklerin sonuçlarını iyileştirmek için ebeveynlerin ve bebeklerinin hem fiziksel hem de duygusal yakınlığının önemini vurgulamaktadır (Coughlin ve ark., 2009; Craig ve ark., 2015; Flacking ve ark., 2012; Montirosso ve ark., 2016). Bebekleri YYBÜ'de tedavi ve bakım alan ebeveynler hem postpartum depresyon ve akut stres bozukluğu hem de travma sonrası stres bozukluğu açısından sağliklı term bebeklerin ebeveynlerinden daha yüksek risk altındadırlar (Miles ve ark., 2007). Bununla birlikte, ebeveynler YYBÜ'deki kendi deneyimleriyle boğulmuş olabilir ve gerekli tamponlamayı sağlamak için bebekleriyle yeterince duygusal olarak etkileşime giremeyebilirler (Janvier ve ark., 2016). Bazı ebeveynler, bebeklerinin ağrılı ve acı veren girişimsel uygulamaları deneyimleyerek, kalp-akciğer canlandırmasını görerek ya da önemsenmediklerini ve sayg1 duyulmadıklarını duyumsadıklarında bebeği üzerinde kontrol kaybı yaşayarak üzülebilirler (Coughlin, 2014). 
YYBÜ'de ideal "tamponlama" ortamının hemşirelerin bakım yaklaşımlarıyla geliştirilerek toksik stres etkenlerinin azaltılabileceği ileri sürülmektedir. Bununla birlikte, hemşireler hiçbir uygulamanın ebeveynlerin bebeklerine sağladiğ 1 paha biçilmez konfor ve bakım tutarlılığının yerini tutamayacağ 1 bilinci ile; ebeveynlere ana tampon olmayı öğretmeli, onları cesaretlendirmeli ve desteklemelidirler. YYBÜ’lerde bebeğin fiziksel sağlığı için stresli olan birçok bakım aktivitesi de gereklidir (Comaru ve Miura, 2009; Lyngstad ve ark., 2014). Doğumdaki hastalığın ya da erken doğum nedeniyle olgunlaşma eksikliğinin önemine bağlı olarak; YYBÜ'de tekrarlayan girişimler, ağn ve acı veren uygulamalar, olumsuz duyusal uyaranlar ve ebeveyn-bebek ayrımı deneyimi "Bebek Tıbbi Travması" olarak tanımlanmıştır (D'Agata ve ark., 2016). Tedavi ve bakım ile ilgili bu deneyimlerin ve kontrolsüz şekilde stresör etkenleriyle karşılaşmanın toksik stresin klasik tanımına uygun olduğu gösterilmiştir (Shonkoff ve ark., 2012). Amerikan Pediatri Akademisi (APA), 2012 y1lında bir bebeğin YYBÜ’ye yatışının sağlık çalışanları tarafından hem bebek hem de ailesi için bir travma olarak görülmesini, travma belirtileri/bulgularının tanımlanması gerektiğini vurgulamış, ve YYBÜ'de ilave bir travmayı önlemek için toksik stresin azaltılması/tamponlanması gerekliğiğini ileri sürmüştür (Shonkoff ve ark., 2012). Günümüzde YYBÜ'de yatan preterm veya kritik hastalığ 1 olan bebekler için; bebek ile ebeveyn arasında ilişkiyi güçlendiren, güvenli bebek bakımını kapsayan ve ebeveyn bağlanmasını kolaylaştıran, bebeğin fiziksel/fizyolojik gelişimi kadar zihinsel gelişimini de önemseyen, biyolojik, psikolojik, sosyal, duygusal gereksinimlerinin karşılandığ "travma bilgisi içeren yaşa uygun bakım" anlayışının benimsenmesi önerilmektedir (Milette ve ark., 2017).

\section{Travma Bilgisi İçeren Yaşa Uygun Bakım}

Travma bilgisi içeren yaşa uygun bakım; bebeğin travmatik YYBÜ deneyimlerini azaltan etkili ve kanıta dayalı bir bakım stratejisidir (Coughlin, 2017). YYBÜ'de travma bilgisi içeren yaşa uygun bakımın kullanımı, Heidelise Als tarafından geliştirilen Sinaktif Teori ve bu teoriye temellendirilmiş Bireyselleştirilmiş Destekleyici Gelişimsel Bakım ve Gelişimsel Bakımın Evreni Modeli'ne dayanmaktadır (Coughlin, 2017; Milette ve ark., 2017).

Travma bilgisi içeren bakımın kökeni olan Polivagal Teori, 1994 yılında Dr. Stephen Porges tarafından açıklanmıştır. Porges (2011) daha önce sempatik ve parasempatik sistem olmak üzere iki başlık altında tanımlanan otonom sinir sistemine sosyal sinir sistemini de ekleyerek bu sistemi üçe ayırmıştır. Sempatik sinir sistemi "kaç ya da savaş" komutlarına uyumlu iken, parasempatik sistem ise hayatta kalma mekanizmasını "yavaşlama/ hareketsizlik" komutu üzerine oluşturmaktadır. Sosyal sinir sistemi; seslendirme, işitme, göz teması ve yüz ifadesi gibi tetikleyicilerden beslenmekte ve sempatik sinir sistemini kontrol altında tutabilme becerisi sağlamaktadır. Sosyal bağlılık olarak da tanımlanan sosyal sinir sisteminin, güvenlik duygusu yaratmada ve sağlıklı komut belirlemede etkisi olduğu ileri sürülmüş, "fizyolojik ve davranışsal durumu karşılıklı olarak düzenleme yeteneği” olarak tanımlanmıştır (Porges, 2011). Bu teori bedene ilişkin basit işlevler ile yüksek zihinsel işlevler arasında (nervus vagus üzerinden) köprü kurmaktadır. Vagus sinirinin dorsal dalı parasempatik sistem ile ilişkili olup pasif savunma ve düşük uyarılma (hypoarousal) özellikleri gösterirken, ventral dalı sosyal sinir sistemi ile ilişkilidir ve tehdit hissedilmeyen durumlarda devreye girmektedir. Bu sistemde, algılanan iç ve dış psikolojik tehdide karşı oluşan tepkiler ilk aşamada savaşma ve kaçma gibi daha aktif eylemleri kapsarken, ağırlaşan tehdit durumlarında donakalma/hareketsizlik ve karşı koymama yolu ile kurtulmaya çalışma öne çıkmaktadır. Oysa tehlikeli bir durumun olmadığı normal sosyal durumda nervus 
vagusun sosyal bağlılığı ile ilgili dalı öne çıkmakta, kişi yakın ilişki kurmaya yatkın olmakta ve organizma da buna göre davranmaktadır (Porges, 2011).

Ventral vagal kompleks kalp ile yüz, baş ve boynun çizgili kaslarını düzenleyen özel viseral eferent yolların nöral kontrolünden sorumludur. $\mathrm{Bu}$ yüz-kalp bağlantısı, strese yanit verirken HPA ekseninin olası olumsuz etkilerini köreltmek için yüz ifadesi, göz temas1 ve sese yansiyan vurgu, tonlama, duraklama, ses perdesi ve şiddetindeki değişimler ile ortaya çıkan sosyal davranışı ve otonomik düzenlemeyi birbirine bağlayan sinirsel platformdur (Porges, 2011). Bu aşama sıralamasında hareket; güvenlik, tehlike veya yaşam tehdidinin "nörosepsiyon"u tarafından yönlendirilir. YYBÜ'de bu nöroseptif her gün bebeklerin, ebeveynlerin ve sağlık çalışanlarının yüzlerinde ve davranışlarında görülür (Porges, 2011; Sanders ve Hall, 2018).

Ten tene temas sonrası küvözüne tekrar konulan yenidoğanın bu duruma tepkisi; sempatik sinir sistemi aktive edilerek "savaş veya kaç" yanıtıyla kalp hızının artması, oksijen satürasyonunun düşmesi, düzensiz solunum ve memnuniyetsizliğini ifade etmek için sağa sola dönme şeklinde gerçekleşir. Sempatik uyarılma kortizol seviyesi ve katekolaminlerin yükselmesine ve bebeğin metabolik hızının artışına, dolayısı ile enerji harcamasina neden olan olumsuz etkileri ortaya çıkarır. Bu uyarılmayı kontrol altına almaya yönelik girişimlerde bulunulmaz ise, bebek ilerleyen süreçte dorsal vagal kompleks aracilı bir hareketsizlik ve teslim olma durumuna geçebilir. $\mathrm{Bu}$ durum genellikle, bebeğin işlemi 'tolere ettiği' şeklinde yanlış yorumlanır. Ancak; bebeğin sempatik sinir sisteminin tükenmesine bağlı olarak bebeğin büyümesi için gerekli olan enerjinin korunması amaciyla dorsal vagal kompleks aracılı istem dışı bir moda geçmesinin daha olası olduğu düşünülmektedir (Sanders ve Hall, 2018).

Ortak Komisyon (The Joint Commission TJC); bireyselleştirilmiş, hasta merkezli, bakım için minimum yeterlilikleri oluşturmak amacıyla 1991'de "yaşa uygun bakım (age- appropriate care)" kavramını ortaya koymuştur (Coughlin, 2014). Bu yeni terminoloji, hastanede yatan preterm ve yüksek riskli yenidoğanlara sürekli ve güvenli yaşa uygun bakım verilebilmesini yasallaştırmış ve yetkilendirmiştir (Coughlin, 2011). Travma bilgisi içeren yaşa uygun bakım; yaşamın başında travmanın fizyolojik, nörobiyolojik ve duygusal sekellerini tanıyan gelişimsel bir kavramdır ve kanıta dayalı, yaşa uygun bakım stratejileri ile travma deneyimine ilişkin zararlı etkileri hafifletmeyi amaçlar. Travma bilgisi içeren yaşa uygun bakım yenidoğanın bireyselliğini kabul eder, tıbbi travma deneyimini bilir ve bebeği destekleyecek yaşa uygun, kanıta dayalı tüm var olan girişimleri içerir. Bu kavram klinik uygulamada yenidoğanın daha sonraki yaşamında temel fiziksel, zihinsel sağlık ve iyiliğini korumak ve güvenliğini sağlamak için uygun bir çevre oluşturur (Coughlin, 2014).

Gelişimsel Bakımın Evreni Modeli hem vücut hem de çevre olan bir nöro-gelişimsel yüzeyi tanımlamaktadır. Modelde tanımlanan yüzey kendiliğinden ve kendinden olmayan, beyin ve çevreyi ayıran bir engel değil, aksine her ikisinin kusursuz bir birleşimi olduğu belirtilmiştir. Bireyler, kendine özgü sınırları olan görünüşte iki ayrı yüzeylere sahip görünmelerine karşın bakım verme sırasında, paylaşılan bir ara yüz üzerinden, birbirlerine yakından ve sorunsuz bir şekilde bağlanmaktadırlar. Her birey diğerinden olumlu veya olumsuz etkilenmektedir (Gibbins ve ark., 2008). Gelişimsel Bakımın Evreni modeliyle çerçevelenmiş olan YYBÜ'de yaşa uygun bakım için temel ölçütler, gelişimsel olarak destekleyici, tüm yenidoğan bakımında ölçülebilir, kanıta dayalı en iyi uygulamaları tanımlamaktadır (Coughlin 2011; Coughlin, 2017; Coughlin ve ark., 2009; Gibbins ve ark., 2008;). YYBÜ'de yaşa uygun bakım için temel ölçütlerin travma bilgisi içeren bakım kavramı ile bütünleştirilmesi, hastanede yatan bebeğin gelişimsel olarak kritik gereksinimlerinin karşılaması ve bütüncül bakım yoluyla sağlığın iyileştirilmesi amaçlanmaktadır 
(Coughlin, 2017). Travma bilgisi ile çalışan sağlık çalışanları her bakım girişimi ile ilgili toksik stresi uygun ve güvenilir biçimde yönetebilmeli ve böylece erken yaşta karşılaşılan travmaya ilişkin yaşam boyu sürecek olumsuz etkileri azaltabilirler (Coughlin, 2014).

Madde Bağımlılı̆̆ı ve Ruh Sağlığı Hizmetleri İdaresi (The Substance Abuse and Mental Health Services Administration SAMHSA), travma bilgisi içeren yaklaşımın altı temel ilkesini geliştirmiştir. Bunlar; akran desteği, ruh sağlığı uzmanlarının rolü, aile merkezli gelişimsel bakım, palyatif ve yas süreci bakımı, taburculuk sonrası izlem ve sağlık çalışanlarının eğitimi şeklindedir (SAMHSA, 2014). Alt1 temel ilke baz alınarak, YYBÜ'de travma bilgisini içeren bakım yaklaşımının geliştirilmesi iki kaynaktan köken almaktadır (Sanders ve Hall, 2018). Birincisi, "YYBÜ Ebeveynlerinin Psikososyal Desteği için Disiplinlerarası Öneriler"dir (Hall ve Hynan, 2015). Öneriler, YYBÜ'de zorlukları nedeniyle bebekleri ve ebeveynleri desteklemeye yönelik sistematik ve çok boyutlu bir yaklaşımı tanımlamaktadır. Bu çok boyutlu yaklaşım Ulusal Perinatoloji Derneği öncülüğünde multidisipliner bir grup profesyonel ve ebeveyn tarafindan literatür incelemesi ve uzmanlar arası görüş birliğinin geliştirilmesi ile elde edilmiştir (Hall ve Hynan, 2015). Ulusal Perinatoloji Derneği'nin önerilerinin temeli, ebeveynler ve bebekler ile, ebeveynler ve sağlık çalışanları arasında, uyumu ve birlikte düzenlemeyi özendirmek için ebeveynin psikolojik alanı'nı oluşturan sosyal etkileşimlerin güçlendirilmesidir (Ash ve Williams, 2016; Hall ve Hynan, 2015). İkincisi, Coughlin ve arkadaşlarının (2009), YYBÜ'de yatan bebeğin beş alanda bakım uygulamaları için kılavuzları ve önerileri özetleyen temel çalışmalarıdır (Coughlin, 2017; Coughlin, 2014; Coughlin ve ark., 2009). Travma bilgisi içeren bakımda yer alan beş temel alan ise; (1) iyileştirici ortamın sağlanması (duyusal-ses, 1şık, tat, koku, dokunma uyaranların kontrol altına alındığ çevre) (2) uykunun korunması (kanguru bakımı, masaj, sarmalama), (3) günlük yaşamın yaşa uygun gelişimsel etkinliklerinin yerine getirmesi (uygun pozisyon verme, cilt bakımı, besleme), (4) ağrı ve stresin yönetimi ve (5) aile merkezli bakım şeklinde bildirilmiştir (Coughlin, 2017; Coughlin, 2016; Coughlin, 2014; Coughlin ve ark., 2009). Ebeveyn-bakım verici işbirliğini tamamen destekleyen Coughlin ve arkadaşlarının (2009) Coughlin 2017; Coughlin 2014; Coughlin ve ark., 2009) önerileri, Ulusal Perinatoloji Birliği önerileriyle büyük ölçüde örtüşmektedir (Coughlin ve ark., 2009; Sanders ve Hall, 2018).

YYBÜ'de çalışan hekimler, hemşireler ve diğer sağlık elemanları dolaylı yolla travmaya uğrayabilmekte ve tükenmişlik, şefkat yorgunluğu, travma sonrası stres bozukluğu ve sekonder travmatik stres sendromuna eğilimli olabilmektedirler (Beck ve Gable, 2012; Braithwaite 2008; Cricco-Lizza 2014; Czaja ve ark., 2012; Profit ve ark., 2014; Weintraub ve ark., 2016). Yapılan bir çalışmada sağlık çalışanlarının esneklik puanları travma sonrası stres bozukluğu semptomları ve duygusal tükenme ile ters orant1lı bulunmuştur (Dalia ve ark., 2013). Sağlık çalışanlarının öz düzenlemesi, ebeveynlerin öz düzenlemelerine yardımcı olma becerileri açısından kritik öneme sahiptir. Sağlık çalışanları ve ebeveynler kendilerini düzenlediklerinde, birbirleriyle ve bebekle olan sosyal bağları güçlendirilir (Sanders ve Hall, 2018). Bebeklere ve ebeveynlerine bakan bütün sağlık çalışanları, düşünce ve duyguları harekete geçirmek yerine "iç deneyim ve düşünmeyi" yansıtan düşünmeyi özendiren bir "farkındalık kültürü” geliştirmekten yararlanabilir (Sanders ve Hall, 2018).

Ebeveynlerin yanı sıra sağlık çalışanları için de bir bakım ve şefkat ortamı yaratmanın önemini kabul eden, genellikle klinik psikologlardan oluşan eğitimli ruh sağlı̆̆ uzmanları giderek artan bir şekilde YYBÜ'de yer almaktadırlar (O'Brien ve ark., 2015). Ebeveynleri anlamaya çalışıldığı kadar, sağlık çalışanlarının anlaşılması ve onlara şefkat gösterilmesi de oldukça önemlidir (Sanders 
ve Hall, 2018). Bebekler, ebeveynler ve sağlık çalışanları sosyal olarak birbirlerine bağlandıklarında ve ventral veya dorsal vagustan en iyi şekilde yararlandıklarında, çevresel, duyusal ve prosedürel stresin en aza indirileceği düşünülmektedir (Sanders ve Hall, 2018).

\section{Sonuç}

Yüksek riskli yenidoğanlara bakım verilirken onların YYBÜ'de tedavi ve bakım aldıkları sürece alacakları bakımın her gün aynı olmayacağı, her bir yenidoğanın bireysel kendine özgü bakım alacağı ve en önemlisi yenidoğanın insani bir bakıma gereksinimi olduğu yaklaşımlarını gündeme getirmiştir. $\mathrm{Bu}$ yaklaşımlara travma bilgisi içeren bakımın eklenmesi ile yüksek riskli yenidoğanların, ebeveynin ve gelişimsel bakımda tartışılmayan sağlık çalışanlarının YYBÜ'de travmadan korunması, ortaya çıkan travma durumunda gerekli tedavi ve bakımların uygulanması ve travma sonrası üçüncül korumanın sağlanmasına yönelik yaklaşımlar ele alınmaktadır. Yüksek riskli yenidoğanlar için olumsuz çocukluk deneyimleri perinatal dönemi ve YYBÜ'yü yansıtırken; ebeveynler ve sağlık çalışanlarının olumsuz çocukluk deneyimleri yaşamlarının birçok evresini kapsayabilir. Ebeveynin travma deneyimi, onun bebeğine bakım vermesinde ve onu yetiştirmesinde oldukça önemlidir. Ayrıca sağlı çalışanının travma deneyimi; kendisine, bebeğe, ebeveyne ve diğer sağlik çalışanlarına verdiği bakımda kritik öneme sahiptir. Sağlıklı ebeveynler ile sağlıklı sağlık çalışanları sayesinde sağlıklı yenidoğanlar oluşabilir. Sağlıklı yenidoğanlar ise sağlıklı toplumun yapı taşlarını oluşturur.

"Güçlü çocukları inşa etmek, kırık yetişkinleri onarmaktan daha kolaydır. / It is easier to build strong children than to repair broken men."

Frederick Douglas
Araştırmanın Etik Yönü/ Ethics Committee Approval: Kaynaklar bölümünde kullanılan literatür gösterilmiştir Hakem/Peer-review: Dış hakem değerlendirmesi.

Yazar Katkısı/Author Contributions: Yazar Katkısı: MCI, MC, ZÇ; Fikir/kavram: MCI, MC; Kaynak tarama; MCI; Makalenin Yazımı: MCI, MC, ZÇ; Eleştirel inceleme: MCI, MC, ZÇ

Çıkar çatışması/Conflict of interest: Yazarlar arasında bir çıkar çatışması yoktur.

Finansal Destek/Financial Disclosure: Finansal destek yoktur.

Çalışma Literatüre Ne Kattı?

- Preterm ve/veya yüksek riskli yenidoğanlara travma bilgisi içeren bakım ile yaklaşılması oldukça önemlidir.

- Travma bilgisi içeren bakım sadece bebeği değil, aynı zamanda ebeveyni ve sağlık çalışanını da içine alan bir yaklaşımdır.

- YYBÜ'de stresin en aza indirilmesi bebekler, ebeveynler ve sağlık çalışanlarının sosyal olarak birbirlerine bağlanmaları ile mümkündür.

\section{Kaynaklar}

Als H, Duffy FH, McAnulty GB, Rivkin MJ, Vajapeyam S, Mulkern RV, et al. (2004). Early Experience alters brain function and structure. Pediatrics, 113, 846-57.

Ash J, Williams ME. (2016). Policies and systems support for infant mental health in the care of fragile infants and their families. Newborn and Infant Nursing Reviews, 16(4), 316-321.

Beck C, Gable R. (2012). A mixed methods study of secondary traumatic stress in labor and delivery nurses. Journal of Obstetric, Gynecologic \&Neonatal Nursing, 41, 747-760.

Braithwaite M. (2008). Nurse burnout and stress in the NICU. Advances in Neonatal Care, 8(6),34-37.

Cohen S, Wills TA. (1985). Stress, socialsupport, and the buffering hypothesis. Psychological Bulletin, 98(2), 310.

Comaru T, Miura E. (2009). Postural support improves distress and pain during diaper change in preterm infants. Journal of Perinatology, 29(7), 504-507.

Coughlin M. (2017). Trauma-informed, neuroprotective care for hospitalised newborns and infants. Infant, 13(5), 176-179. 
Coughlin ME. (2016). Trauma-Informed Care in the NICU: Evidenced-Based Practice Guidelines For Neonatal Clinicians. Springer Publishing Company.

Coughlin M. (2014). Transformative nursing in the NICU: Trauma-informedage-appropriate care. Springer Publishing Company.

Coughlin ME. (2014). Yenidoğan Yoğun Bakım Ünitelerinde Dönüşümsel Hemşirelik Travma Bilgisi İçeren Yaşa Uygun Bakım. (Çev Eds Yardımcı F, Akçay Didişen N, Başbakkal Z.), Nobel Akademik Yayınc1lı, İstanbul, s.3-149

Coughlin M. (2011). Age-appropriatecare of the prematüres and critically ill hospitalized infant NANN guideline for practice. Retrieved from Glenview, IL: National Association of Neonatal Nurses. p.1-10.

Coughlin M, Gibbins S, Hoath S. (2009). Core measures for developmentally supportive care in neonatal intensive care units: theory, precedence and practice. Journal of Advanced Nursing, 65, 2239-2248.

Craig J, Glick C, Phillips R, Hall S, Smith J, Browne J. (2015). Recommendations for involving the family in developmental care of the NICU baby. Journal of Perinatology, 35, S5-S8.

Cricco-Lizza R. (2014). The need to nurse the nurse: emotional labor in Neonatal Intensive Care. Qualitative Health Research, 24(5), 615628.

Czaja A, Moss M, Mealer M. (2012). Symptoms of post-traumatic stress disorder among pediatric acute care nurses. Journal of Pediatric Nursing, 27(4), 357-365.

D'Agata AL, Young EE, Cong X, Grasso DJ, McGrath JM, Forsythe PL. (2016). Infant medical trauma in the neonatal intensive care unit (IMTN). Advances in Neonatal Care, 16(4), 289-297.

Dalia C, Abbas K, Colville G, Brierley J. (2013). Resilience, post-traumatic stress, burnoutand coping in medical staff on the paediatric and neonatal intensive care unit (P/NICU) - a survey. Archives of Disease in Childhood, 98, A26-A27.

Dünya Sağlık Örgütü. (2018). Preterm birth. Erişim tarihi: 28.06.2020, https://www.who.int/newsroom/fact-sheets/detail/preterm-birth.
Felitti V, Anda R, Nordenberg D, Williamson D, Spitz A, Edwards V, et al.(1998). Relationship of child hood abuse and household dysfunction to many of the leading causes of death in adults. The Adverse Childhood Experiences (ACE) Study. American Journal of Preventive Medicine, 14(4), 245-258.

Flacking R, Lehtonen L, Thomson G, Axelin A, Ahlqvist S, Moran VH, et al.(2012). Closeness and separation in neonatal intensivecare. Acta Paediatrica, 101 (10), 1032-1037.

Gibbins S, Hoath SB, Coughlin M, Gibbins A, Franck L. (2008). The universe of developmental care: a new conceptual model for application in the neonatal intensive care unit. Advances in Neonatal Care, 8(3), 141-147.

Grasso DJ, Ford JD, Briggs-Gowan MJ. (2013). Early life trauma exposure and stress sensitivity in young children. Journal of Pediatric Psychology, 38(1), 94-103.

Gunnar MR, Donzella B. (2002). Social regulation of the cortisol levels in early human development. Psychoneuroendocrinology, 27(12), 199-220.

Hall S, Hynan M. (2015). Interdisciplinary recommendations for the psychosocial support of NICU parents. Journal of Perinatology, 35, S29-S36.

Janvier A, Lantos J, Aschner J, Barrington K, Batton B, Batton D, et al. (2016). Stronger and more vulnerable: a balanced view of the impacts of the NICU experience on parents. Pediatrics, $138(3), 1-4$.

Johnstone JM, Carter JD, Luty SE, Mulder RT, Frampton CM, Joyce PR. (2013). Maternal care and paternal protection influence response to psychotherapy treatment for adult depression. Journal of Affective Disorders, 149, 221-229.

Liu L, Oza S, Hogan D, Chu Y, Perin J, Zhu J, et al. (2016). Global, regional, and national causes of under 5 mortality in 2000-15: an updated systematic analysis with implications for the Sustainable Development Goals. Lancet, 388(10063), 3027-3035.

Lyngstad LT, Tandberg BS, Storm H, Ekeberg BL, Moen A. (2014). Does skin-to-skin contact reduce stress during diaper change in preterm infants?. Early Human Development, 90(4), 169-172. 
Miles S, Holditch-Davis D, Schwartz T, Scher M. (2007). Depressive symptoms in mothers of prematurely born infants. Journal of Developmental \& Behavioral Pediatrics, 28(1), 36-44.

Milette I, Martel MJ, Ribeiro da Silva M, Coughlin M. (2017). Guidelines for the institutional implementation of developmental neuroprotective care in the NICU. Part A: background and rationale. A joint position statement from the CANN, CAPWHN, COINN, NANN. Canadian Journal of Nursing Research, 49(2), 46-62.

Montirosso R, Casini E, Del Prete A, Zanini R, Bellu R, Borgatti R. (2016). NEO-ACQUA Study Group. Neonatal developmental care in infant pain management and internalizing behaviors at 18 months in prematurely born children. European Journal of Pain, 20, 10101021.

Montirosso R, Provenzi L. (2015). Implications of epigenetics and stress regulation on research and developmental care of preterm infants. Journal of Obstetric, Gynecologic, \& Neonatal Nursing, 44,174-182.

O’Brien K, Bracht M, Robson K, Ye XY, Mirea L, Cruz M, ve ark. (2015). Evaluation of the Family Integrated Care model of neonatal intensive care: a cluster randomized controlled trial in Canada and Australia. BMC Pediatrics, 15,210 .

Porges SW. (2011). The Polyvagal Theory: Neurophysiological Foundations of Emotions, Attachment, Communication, and SelfRegulation. New York: Norton Books. p.1-146.

Profit J, Sharek P, Amspoker A, Kowalkowski M, isbet C, Thomas E, ve ark. (2014). Burnout in the NICU setting and its relation to safety culture. BMJ Quality \& Safety, 10, 806-813.

Sağlık Bakanlığı. (2019). Prematüre Doğumlar. Erişim tarihi: 28.06.2020, https://hsgm.saglik.gov.tr/depo/birimler/cocuk_ ergen_db/dokumanlar/istatistikler/premature.pdf

Sanders MR, Hall SL. (2018). Trauma-informed care in the newborn intensive care unit: promoting safety, security and connectedness. Journal of Perinatology, 38(1), 3-10.
Selye H. (1976). Forty years of stress research: principal remaining problems and misconceptions. Canadian Medical Association Journal, 115, 53-56.

Shonkoff J, Garner A, Siegel B, Dobbins M, Earls M, Garner A, ve ark. (2012). The lifelong effects of early childhood adversity and toxic stress. Pediatrics, 129(1), e232.

Sprenrath MA, Clarke ME, Kutcher S. (2011). The science of brain and biological development: Implications for mental health research, practice and policy. Journal of Canadian Academy of child and Adolescent Psychiatry, 20(4), 298304.

Substance Abuse and Mental Health Services Administration (2014). SAMHSA's Concept of Trauma and Guidance for a Trauma-Informed Approach. Substance Abuse and Mental Health Services Administration: Rockville, MD, eport No.: HHS Publication No. (SMA) 14-4884.

Taş Arslan F, Akkoyun S.(2019). Yenidoğan Bütünleştirici Gelişimsel Bakım Modeli: Nöroprotektif Aile Merkezli Gelişimsel Bakım için Yedi Temel Ölçüm. Ordu University Journal of Nursing Studies, 2(3),170-180.

Weber A, Harrison TM. (2019). Reducing toxic stress in the neonatal intensive care unit to improve infant outcomes. Nursing Outlook, 67(2), 169-189.

Weber AM, Harrison TM, Steward DK (2012). Schore's regulation theory: maternal-infant interaction in the NICU as a mechanism for reducing the effects of allostatic load on neurodevelopment in premature infants. Biological Research for Nursing, 14(4), 375386.

Weintraub A, Geithner E, Stroustrup A, Waldman E. (2016). Compassion fatigue, burnout and compassion satisfaction in neonatologists in the US. Journal of Perinatology, 36, 1021-1026.

Victoria N, Murphy A. (2016). The long-term impact of early life pain on adult responses to anxiety and stress: historical perspectives and empirical evidence. Experimental Neurology, 275(Part 2), 261-273. 